\title{
Intravenous leiomyomatosis of the uterus: A study of ten cases
} \author{
M Hedfi ${ }^{3}$, L Charfi ${ }^{2}$ and R Doghri ${ }^{2}$ \\ 1Pathology Department, Zaghouan Hospital, Tunisia \\ ${ }^{2}$ Pathology Departement, Salah Azaiez Institute, Tunisia \\ ${ }^{3}$ Surgery Department, Zaghouan Hospital, Tunisia
}

R Sellami Dhouib1, S Bouslama ${ }^{1 *}$, G Sahraoui' ${ }^{2}$ N Feriani ${ }^{3}$,

Received: 26 August, 2020

Accepted: 18 September, 2020

Published: 19 September, 2020

*Corresponding author: S Bouslama, Pathology Department, Zaghouan Hospital, Tunisia, E-mail: sirine.bouslema@hotmail.fr

https://www.peertechz.com

Check for updates

\begin{abstract}
Intravenous leiomyomatosis of the uterus (IVL) is a rare type of uterine leiomyoma. It is defined by the presence of benign smooth muscle within vascular spaces outside the confines of a leiomyoma, free floating within the lumen or adherent to the vessel wall. We report 10 cases of IVL to discuss the clinical, radiological, histological, therapeutic and prognostic features of this entity. We concluded that, in line with literature, IVL can have a malignant behaviour. The treatment is based on surgery. Hormonal treatment is recommended. Large sampling of peritumoral tissue in uterine leiomyomas can lead to early diagnosis of IVL. Follow up is mandatory to detect possible recurrence or extra-pelvic extension.
\end{abstract}

\section{Introduction}

Intravenous leiomyomatosis of the uterus (IVL) is a rare type of uterine leiomyoma. Less than 200 cases have been reported in the literature [1]. Most of them were individual case reports. IVL is defined by the presence of benign smooth muscle within vascular spaces outside the confines of a leiomyoma, free floating within the lumen or adherent to the vessel wall [2]. Etiopathogenesis is still unknown. Two hypothesis may explain this pathology, invasion of the vascular lumen by smooth muscle cells of the venous wall [3] or by a uterine leiomyoma [4].

Through a study of 10 cases of uterine IVL, we discuss its clinical, radiological, histological, therapeutic and prognostic features.

\section{Materials and methods}

All the cases of histologically diagnosed IVL in The Patholology Department in Salah Azaiez Institute in Tunisia From 1992 to 2006 were enrolled in our study. We reviewed clinical characteristics, radiologic findings, treatment, histologic examination and follow-up.

All of the histology slides were checked by 2 pathologists.
Immunohistochemistry on paraffin embedded blocks using CD31 and CD 34 was used to confirm IVL diagnosis.

\section{Results}

From 1992 to 2006, 10 cases of IVL were found.

1) Age of the patients: The mean age of patients was 45 years, with a range from 38 to 59 years.

2) Hormonal status: One patient $(10 \%)$ was experiencing menopause, 3 patients $(30 \%)$ were perimenopausal women. The six other patients $(60 \%)$ were women of childbearing age.

3) Symptoms: Six patients had vaginal bleeding $(60 \%)$ : metrorrhagia in 3 cases $(30 \%)$, menorrhagia in 2 cases $(20 \%)$ and menormatrorrhagia in 1 case $(10 \%)$. Pelvic pain was reported in 5 cases $(50 \%)$. One patient $(10 \%)$ had pollakiuria with no urinary tract infection, 1 patient $(10 \%)$ had lumbar pain due to left ureteral compression.

4) Physical examination: Physical examination showed an enlarged uterus in 4 cases $(40 \%)$, a pelvic mass in 1 case $(10 \%)$, 2 abdominal masses in 1 case $(10 \%)$.

5) Radiologic findings: Pelvic ultrasonography was performed in 8 cases. It showed one mass in 7 cases $(87,5 \%)$, 
numerous masses in 1 case $(12,5 \%)$. Hemorrhage and necrosis were found in 1 case $(12,5 \%)$. Ureteral compression was found in 1 case $(12,5 \%)$.

6) Surgical treatment: Eight patients underwent hysterectomy $(80 \%)$. Associated left salpingoophorectomy was performed in 2 cases $(20 \%)$, associated bilateral salpingoophorectomy in 4 cases $(40 \%)$. Two patients had myomectomy $(20 \%)$.

7) Gross examination: On gross examination, 1 myoma was found in 3 cases ( $30 \%)$, multiple myomas were found in 7 cases $(70 \%)$. The size of the tumors ranged from 3 to $10 \mathrm{~cm}$. Tumors were firm, sharply demarcated, white and whorled like classic leiomyomas. Peritumoral retraction clefting was noted in 3 cases $(30 \%)$.

8) Histologic examination: On histology the tumors had a fascicular pattern of smooth muscle bundles. Mitoses didn't exceed 3M/10 HPF. Cells grew inside lumen of uterine veins. In all the cases, there was peritumoral retraction clefting (Figure A, B, C, D).

9) Immunohistochemistry: Immunohistochemistry using CD 34 and CD 31 was performed in all the cases. It was positive around the tumor, around intra vascular tumor cells in all the patients (Figure $\mathrm{C}$ ). Caldemone was performed in 3 cases, all of them were positive (Figure F).

10) Hormonal treatment: None of our patients had hormonal treatment after surgery.

11) Follow-up: One patient had abdominal pain 3 months after hysterectomy and bilateral adnexectomy. Radiologic

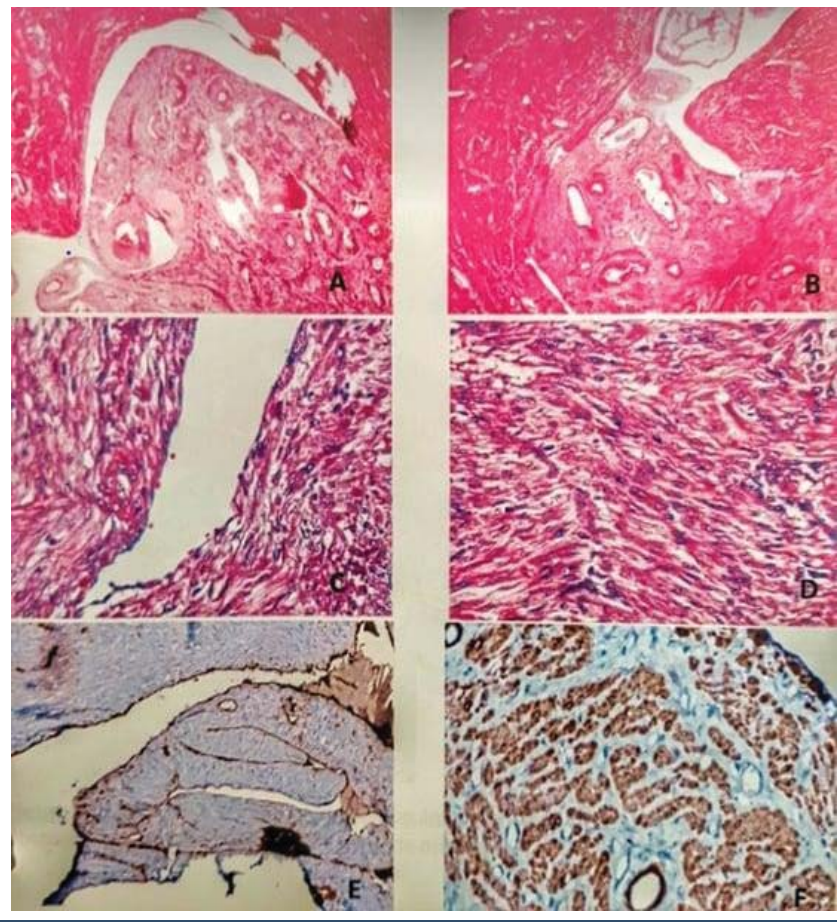

Figure: A, B: intra-venous tumor cells.

$C, D$ : high cellularity of the tumor

E: CD 34 staining.

F: Caldesmone staining. examination showed retroperitoneal, latero-aortic lesions and retro-peritoneal lymphatic localization of IVL. After complete excision, immunohistochemistry was performed. Tumor cells were positive for smooth muscle actin and caldesmone, CD117 was negative.

For all the patients there were neither mortality nor recurrence. The average period of follow-up was 2 years.

\section{Discussion}

IVL generally occurs in premenopausal women with an average age of 43-45 years [5-7]. The most frequent symptoms are vaginal bleeding or pelvic pain. Physical examination shows usually enlarged uterus or pelvic mass.

Pelvic CT and MRI have the highest performance in the diagnosis of IVL. On MRI, IVL appears as a solid, tubular or "sausage-like" intravascular lesion. CT findings are uterine leiomyomas with hypoattenuating intravascular filling defect [8]. Our patients had only pelvic ultrasonography which showed classical features of uterine leiomyoma. Pelvic MRI wasn't performed.

Hysterectomy and bilateral salpingoophorectomy are considered as the gold-standard treatment by many studies [9]. Other authors propose complete resection of any intravenous extension, including intracardiac IVL [10].

On gross examination, multiple myomas are associated with worm-like plugs in parametrial vessels [11]. IVL is a histologic diagnosis. It consists of an intravascular proliferation of smooth muscle tumor with a benign cytology [12]. On immunohistochemistry, cells are positive for estrogen receptors, progesterone receptors, smooth muscle actin and caldesmone. In our study, immunohistochemistry using estrogen receptors and progesterone receptors was executed in 3 cases, all of them tested positive for these antibodies.

Sampling peritumoral tissue and the soft tissue of the lower uterine segment below the peritoneal reflection is suggested to diagnose early IVL [6]. Otherwise, many cases might be misdiagnosed as classical leiomyoma.

Recurrence rate of IVL was estimated at $30 \%$ in many studies [13]. The tumor cells can reach the inferior vena cava, the right heart and the lungs. In a series of 14 cases of IVL [14], Su et al. reported for the first time a case of involvement in the superior vena cava and 5 cases of postoperative thrombosis. Thereby, surveillance imaging of the venous system and heart are mandatory with no prevailing consensus. In our study, one patient had a local recurrence that was excised. For all the patients there were neither mortality nor recurrence. The average period of follow-up was 2 years.

Post-operative hormonal treatment was suggested and evaluated by many reviews. Alternatives are: antiestrogenic therapy, gonadotropin-releasing hormone agonists [15], and aromatase inhibitors. The results of hormonal therapies are mixed. They are particularly indicated in case of incomplete excision [16].

Citation: Dhouib RS, Bouslama S, Sahraoui G, Feriani N, Hedfi M, et al. (2020) Intravenous leiomyomatosis of the uterus: A study of ten cases. J Surg Surgical Res 6(2): 143-145. DOI: https://dx.doi.org/10.17352/2455-2968.000117 


\section{Conclusion}

IVL is a benign pathology who may have a malignant behaviour. Sampling around uterine leiomyomas is suggested to prevent misdiagnosis as a classical leiomyoma. Surveillance imaging of the venous system and heart are mandatory since migration of tumor cells can occur.

\section{References}

1. A Low HY (2017) Intravenous leiomyomatosis of the uterus: A clinicopathological analysis of nine cases and literature review. Taiwan J Obstet Gynecol 56: 362-365. Link: https://bit.ly/2ZO07oh

2. Kurman RJ (2014) WHO classification of tumours of female reproductive organs. Fourth Edition 137. Link: https://bit.ly/3iHIRIp

3. Knauer E (1903) Beitrag zur Anatomie der Uterusmyome. Beur Geburtshilfe Gynaekol 1: 695. Link: https://bit.ly/2ZNpmac

4. Sitzenfry A (1911) Uber Venenmyome des Uterus mit intravaskularem Wachstum. Z Geburtshilfe Gynaekol 68: 1-25.

5. Valdés Devesa V, Conley CR, Stone WM, Collins JM, Magrina JF (2013) Update on intravenous leiomyomatosis: report of five patients and literature review. Eur J Obstet Gynecol Reprod Biol 171: 209-213. Link: https://bit.ly/3mz96TO

6. Du J, Zhao X, Guo D, Li H, Sun B (2011) Intravenous leiomyomatosis of the uterus: a clinicopathologic study of 18 cases, with emphasis on early diagnosis and appropriate treatment strategies. Hum Pathol 42: 1240-1246. Link: https://bit.ly/32LA2Ip

7. Clay TD, Dimitriou J, McNally OM, Russell PA, Newcomb AE (2013) Intravenous leiomyomatosis with intracardiac extension - a review of diagnosis and management with an illustrative case. Surg Oncol 22: e44-e52. Link: https://bit.ly/35KmD56
8. Bender LC, Mitsumori LM, Lloyd KA, Stambaugh LE (2011) AIRP best cases in radiologic-pathologic correlation: intravenous leiomyomatosis. Radiographics 31: 1053-1058. Link: https://bit.ly/2EfBppa

9. Yu-Feng $L$ (2011) Intravenous leiomyomatosis of the uterus with extension to the right heart. Cardiovasc Ultrasound 9: 25. Link: https://bit.ly/3ccBINO

10. Wang J, Yang J, Huang H, Li Y, Miao Q (2012) Management of intravenous leiomyomatosis with intracaval and intracardiac extension. Obstet Gynecol 120: 1400-1406. Link: https://bit.ly/2RCu8CP

11. Ordulu Z, Nucci MR, Dal Cin P, Hollowell ML, Otis CN (2016) Intravenous leiomyomatosis: an unusual intermediate between benign and malignant uterine smooth muscle tumors. Mod Pathol 29: 500-510. Link: https://bit.ly/32GpGcF

12. Ip PP, Tse KY, Tse KY (2010) Uterine smooth muscle tumors other than the ordinary leiomyomas and leiomyosarcomas: a review of selected variants with emphasis on recent advances and unusual morphology that may cause concern for malignancy. Adv Anat Pathol 17: 91-112. Link: https://bit.ly/3klkhOa

13. Fasih N, Prasad Shanbhogue AK, Macdonald DB, Fraser-Hill MA, Papadatos D (2008) Leiomyomas beyond the uterus: unusual locations, rare manifestations. Radiographics 28: 1931-1948. Link: https://bit.ly/3mxIrac

14. Su Q, Zhang X, Zhang H, Liu Y, Dong Z, et al. (2020) Intravenous Leiomyomatosis of the Uterus: A Retrospective Single-Center Study in 14 Cases. Biomed Res Int 2020: 9758302. Link: https://bit.ly/35LLwgF

15. Correia P, Castro A, Rocha A, Freitas D, Carnide C, et al. (2016) Pelvic Intravenous Leiomyomatosis - Case Report. Rev Bras Ginecol Obstet 38: 412 415. Link: https://bit.ly/3ilrOWU

16. Doyle MP, Li A, Villanueva Cl, Peeceeyen SC, Cooper MG, (2015) Treatment of Intravenous Leiomyomatosis with Cardiac Extension following Incomplete Resection. Int J Vasc Med 2015: 756141. Link: https://bit.ly/35QNGM3
Discover a bigger Impact and Visibility of your article publication with Peertechz Publications

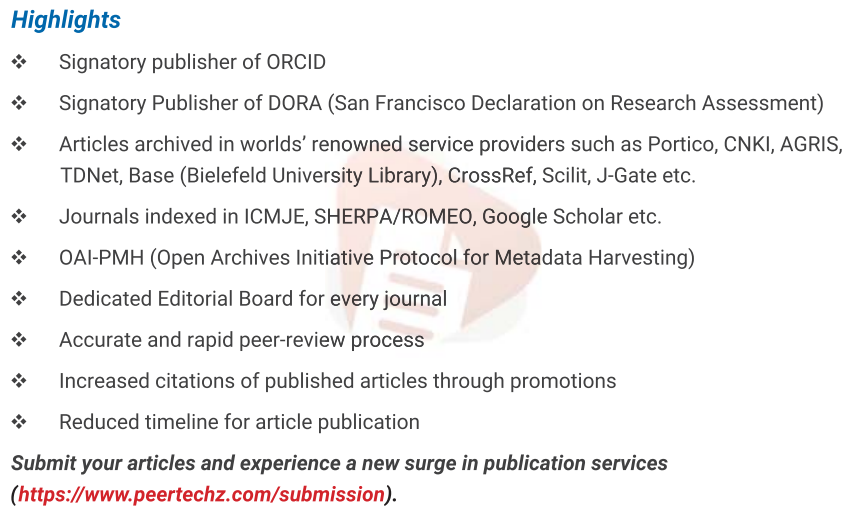

Peertechz journals wishes everlasting success in your every endeavours.

Copyright: ( 2020 Dhouib RS, et al. This is an open-access article distributed under the terms of the Creative Commons Attribution License, which permits unrestricted use distribution, and reproduction in any medium, provided the original author and source are credited. 